\title{
Similarities and differences in inflammatory mechanisms of asthma and COPD
}

\section{Educational aims}

1 To discuss the similarities and differences in inflammation between COPD and asthma

1 To consider the clinical relevance of these differences

1 To speculate about the therapeutic implications of this basic research

Asthma and chronic obstructive pulmonary disease (COPD) are both characterised by airway obstruction, which is variable and reversible in asthma but is progressive and largely irreversible in COPD. In both diseases, there is chronic inflammation of the respiratory tract, which is mediated by the increased expression of multiple inflammatory proteins, including cytokines, chemokines, adhesion molecules, inflammatory enzymes and receptors. In both diseases there are acute episodes or exacerbations, when the intensity of this inflammation increases. The similarity between these airway diseases prompted the suggestion in the 1960s that asthma and COPD are part of a spectrum of a common disease (chronic obstructive lung disease) and this came to be known as the "Dutch hypothesis". This was countered by the "British hypothesis", which maintained that these diseases were separate entities; the debate continues today, with evidence both for and against these two views $[1,2]$.

Despite the similarity of some clinical features of asthma and COPD, there are marked differences in the pattern of inflammation that occurs in the respiratory tract, with different inflammatory cells recruited, different mediators produced, distinct consequences of inflammation and differing responses to therapy. In addition, the inflammation seen in asthma is mainly located in the larger conducting airways, although small airways may also be involved in more severe disease, but the lung parenchyma is not affected. By contrast, COPD predominantly affects the small airways and lung parenchyma, although similar inflammatory changes may also be found in larger airways $[3,4]$. These differences in disease distribution may partly reflect the distribution of inhaled inciting agents, such as allergens in asthma and tobacco smoke in COPD. In both diseases, there are different recognised clinical phenotypes. Most patients with asthma are atopic (extrinsic asthma), but a few patients are nonatopic (intrinsic asthma) and these patients often have more severe disease [5]. There is a spectrum of asthma severity, which tends to be maintained throughout life [6]. Approximately $5 \%$ of patients have severe asthma that is difficult to control with maximal inhaler therapy and for whom new therapeutic approaches are needed. The main types of COPD are the development of small airway obstruction and emphysema, which can occur alone or together, but both involve progressive airflow limitation and are usually caused by tobacco smoke.

The differences in inflammation between asthma and COPD are linked to differences in the immunological mechanisms of these two diseases (figs 1 and 2). There have been several recent important advances in our understanding of the immunopathology of asthma and COPD [7]. T-cells play a crucial role in both asthma and COPD and it is now recognised that different subsets are involved

\section{P.J. Barnes}

Respiratory Medicine, Imperial College London Airway Disease,

National Heart \& Lung Institute, Dovehouse St,

SW3 $6 L Y$

London, UK

p.j.barnes@imperial.ac.uk

\section{Competing interests}

P.J. Barnes has received funding for lectures and research from Astra Zeneca, GlaxoSmithKline, Boehringer Ingelheim, Novartis and Pfizer. 


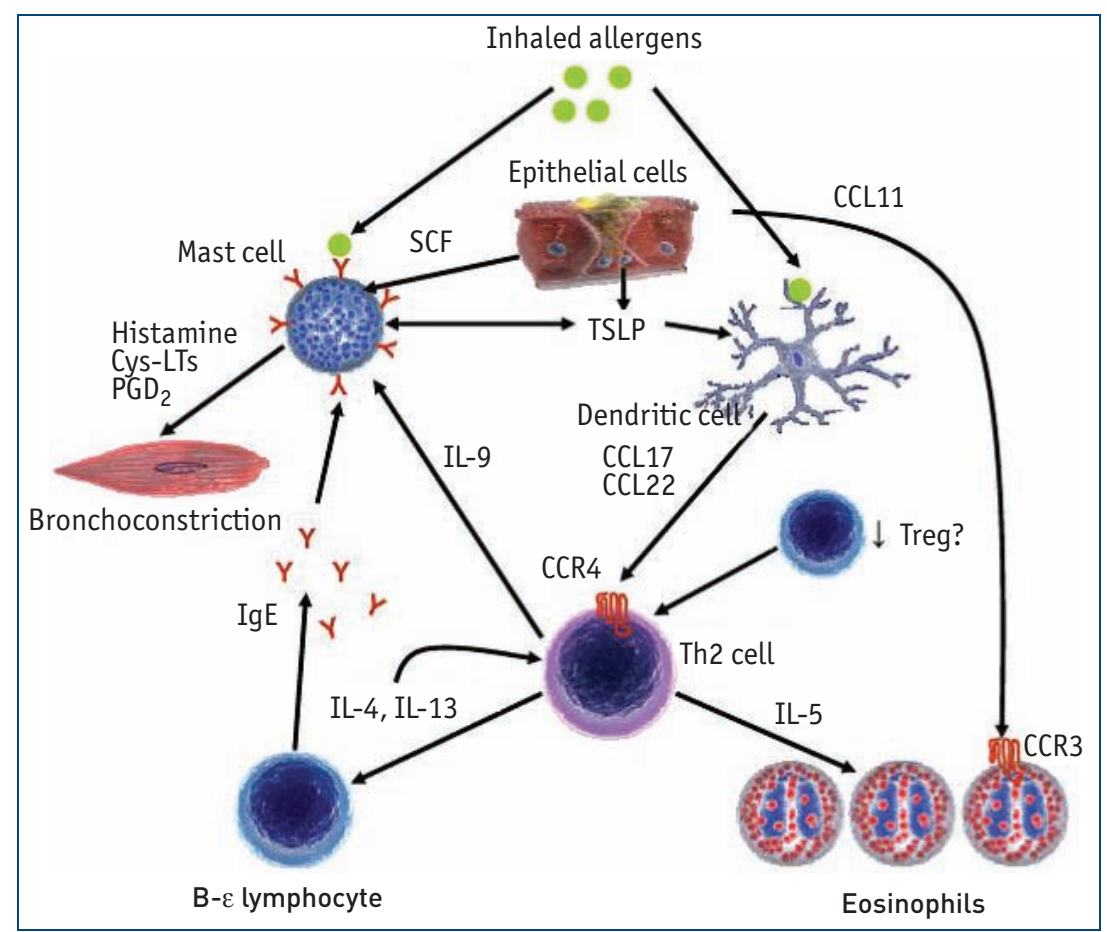

\section{Figure 1}

Inflammatory and immune cells involved in asthma. Inhaled allergens activate sensitized mast cells by crosslinking surface-bound immunoglobulin (Ig)E molecules to release several bronchoconstrictor mediators, including cysteinyl-leukotrienes (cys-LT) and prostaglandin D2 (PGD2). Epithelial cells release stem-cell factor (SCF), which is important for maintaining mucosal mast cells at the airway surface. Allergens are processed by myeloid dendritic cells, which are conditioned by thymic stromal lymphopoietin (TSLP) secreted by epithelial cells and mast cells to release the chemokines CC- 31 chemokine ligand (CCL)17 and CCL22, which act on CC-chemokine receptor 4 (CCR4) to attract Thelper 2 (Th-2) cells. Th-2 cells have a central role in orchestrating the inflammatory response in allergy through the release of interleukin-4 (IL-4) and IL-13 (which stimulate B-cells to synthesise IgE) IL-5 (which is necessary for eosinophilic inflammation) and IL-9 (which stimulates mast-cell proliferation). Epithelial cells release CCL11, which recruits eosinophils via CCR3. Patients with asthma may have a defect in regulatory T-cells (Treg), which may favour further Th2-cell proliferation.

in orchestrating inflammation in these two diseases, resulting in different inflammatory and structural consequences. B-cells also play an important role, although this remains poorly understood in COPD. The appreciation that similar immune mechanisms are involved in both asthma and COPD has important implications for the development of new therapies for these troublesome diseases.

\section{Inflammatory cells and mediators}

There are many differences between mild asthma and COPD in the type of inflammation that occurs in the lungs, with a different range of inflammatory cells and mediators being implicated $[8,9]$. However, many of the cytokines and chemokines that are secreted in both asthma and COPD are regulated by the transcription factor nuclear factor (NF)- $\kappa \mathrm{B}$, which is activated in airway epithelial cells and macrophages in both diseases and may have an important role in amplifying airway inflammation.

\section{Histopathology}

The histological appearance of airways from asthmatic individuals is very different from the changes that are found in patients with COPD (table 1, fig. 3). Bronchial biopsies from asthmatic subjects reveal an infiltration of eosinophils, activated mucosal mast cells at the airway surface and activated T-cells. There are characteristic structural changes with collagen deposition under the epithelium, which is sometimes described as basement-membrane thickening and is found in all patients, and thickening of the airway smooth-muscle layer as a result of hyperplasia and hypertrophy, which is more commonly seen in patients with severe asthma. Epithelial cells are often shed from patient biopsies compared with normal control biopsies, as they are friable and more easily detach from the basement membrane during the biopsy procedure. In addition, there is an increase in the number of blood vessels (angiogenesis) in response to increased secretion of vascularendothelial growth factor (VECF) [10]. Mucus hyperplasia is commonly seen in biopsies from asthmatic patients, with an increase in the number of mucus-secreting goblet cells in the epithelium and an increase in the size of submucosal glands [11].

In bronchial biopsies, small airways and lung parenchyma from patients with COPD, there is no evidence for mastcell activation, but there is an infiltration of T-cells and increased numbers of neutrophils, particularly in the airway lumen [12]. Subepithelial fibrosis is not apparent but fibrosis does occur around small airways and is thought to be a major factor that contributes to the irreversible airway narrowing that is characteristic of this disease [13]. Airway smooth muscle is not usually increased in COPD patients compared with normal airways, and airway epithelial cells may show pseudostratification as a result of chronic irritation from inhaled cigarette smoke or other irritants and the release of epithelial-cell growth factors. As in asthma, there is mucus hyperplasia and increased expression of mucin genes in biopsies from patients with COPD [14]. A marked difference between COPD and asthma is the destruction of alveolar walls (emphysema) that occurs in COPD as a 
result of protease-mediated degradation of connective tissue elements, particularly elastin, as well as apoptosis of type-l pneumocytes and possibly endothelial cells $[15,16]$. In addition, the production of elastolytic enzymes, such as neutrophil elastase and particularly several matrix metalloproteinases (MMPs), is increased in the lungs of COPD patients [17], and there may be a reduction in the levels of antiproteinases, such as $\alpha_{1}$-antitrypsin, as seen in a rare form of emphysema cause by a congenital deficiency of $\alpha 1$-antitrypsin [18].

\section{Mast cells}

Mast cells play a key role in asthma through the release of several bronchoconstrictors, including histamine, which is preformed and stored in granules, as well as the lipid mediators leukotriene $C_{4}, D_{4}$ and $E_{4}$ and prostaglandin $D_{2}$, which are synthesised upon mastcell activation. The release of these mediators may account for the variable bronchoconstriction seen in asthma, as these mediators are released by various environmental triggers, such as allergens, and an increase in osmolality as a result of increased ventilation during exercise. Mucosal mast cells are recruited to the surface of the airways by stem-cell factor (SCF) released from epithelial cells, which acts on KIT receptors expressed by the mast cells [19]. Mast cells also release cytokines that are linked to allergic inflammation, including interleukin (IL)-4, IL-5 and IL-13 [20]. The presence of mast cells in the airway smooth muscle has been linked to airway hyperresponsiveness in asthma [21], as patients with eosinophilic bronchitis have a similar degree of eosinophilic inflammation to that found in asthmatics and also have subepithelial fibrosis, but they do not show hyperresponsiveness, which is the physiological hallmark of asthma. By contrast, mast cells do not seem to play a role in COPD, which may explain the lack of variable bronchoconstriction in this disease.

\section{Granulocytes}

The inflammation that occurs in asthma is often described as eosinophilic, whereas that occurring in COPD is described as neutrophilic. These differences reflect the secretion of different chemotactic factors in these diseases. In asthma, eosinophil chemotactic factors, such as CCchemokine ligand (CCL11, also known as eotaxin-1) [11] and related CC-chemokines, are

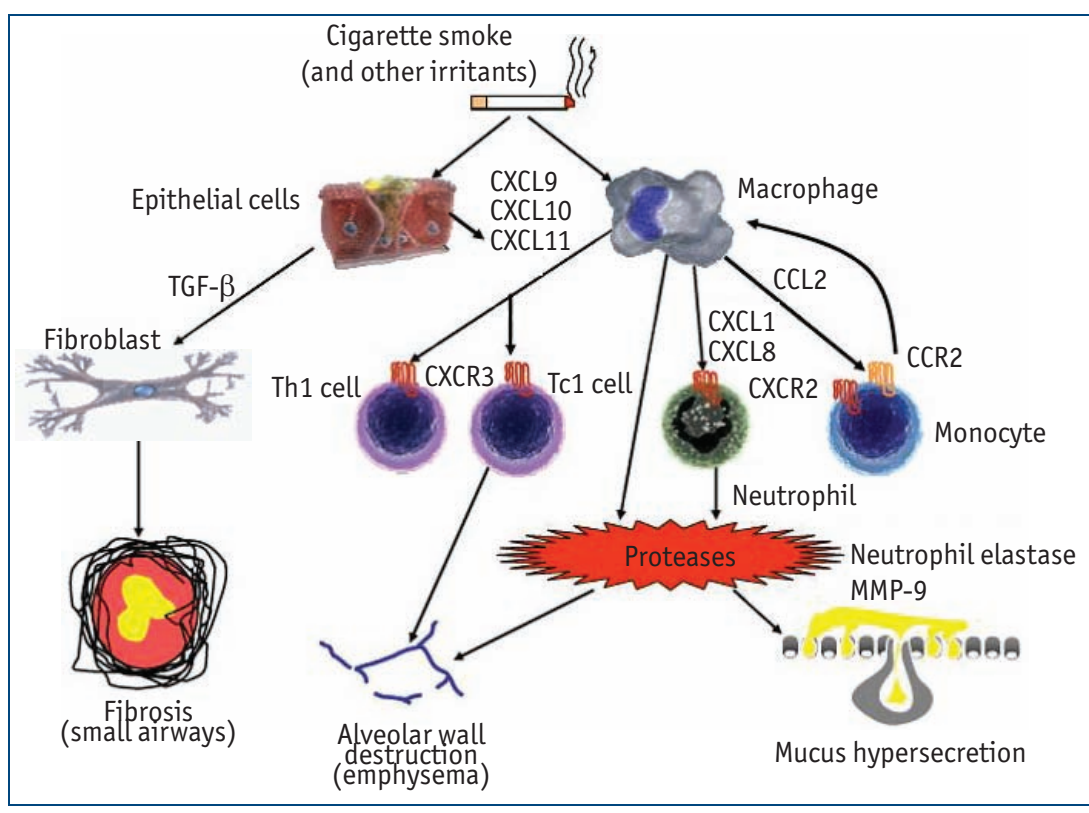

\section{Figure 2}

Inflammatory and immune cells involved in chronic obstructive pulmonary disease (COPD). Inhaled cigarette smoke and other irritants activate epithelial cells and macrophages to release several chemotactic factors that attract inflammatory cells to the lungs, including CC-chemokine ligand 2 (CCL2), which acts on CC-chemokine receptor 2 (CCR2) to attract monocytes, CXCchemokine ligand 1 (CXCL1) and CXCL8, which act on CCR2 to attract neutrophils and monocytes (which differentiate into macrophages in the lungs) and CXCL9, CXCL10 and CXCL11, which act on CXCR3 to attract Thelper 1 (Th1) cells and type 1 cytotoxic T-cells (TC1 cells). These inflammatory cells together with macrophages and epithelial cells release proteases, such as matrix metalloproteinase 9 (MMP9), which cause elastin degradation and emphysema. Neutrophil elastase also causes mucus hypersecretion. Epithelia cells and macrophages also release transforming growth factor (TGF), which stimulates fibroblast proliferation, resulting in fibrosis in the small airways.

mainly secreted by airway epithelial cells. The functional role of eosinophils in asthma is not clear and the evidence that links their presence to airway hyperresponsiveness has been questioned by the finding that administration of IL-5specific blocking antibodies that markedly reduce

\section{Table 1 Differences in histopathology between asthma and chronic obstructive pulmonary disease (COPD) airways}

$\begin{array}{lll} & \text { Asthma } & \text { COPD } \\ \text { Mast cells } & \text { Increased and activated } & \text { Normal } \\ \text { Dendritic cells } & \text { Increased } & \text { Uncertain } \\ \text { Eosinophils } & \text { Increased } & \text { Normal } \\ \text { Neutrophils } & \text { Normal } & \text { Increased } \\ \text { Lymphocytes } & \text { Th2 } & \text { Th1, Tc1 } \\ \text { Epithelium } & \text { Often shed } & \text { Pseudostratified } \\ \text { Goblet cells } & \text { Increased } & \text { Increased } \\ \text { Airway smooth muscle } & \text { Increased } & \text { Minimal increase } \\ \text { Airway vessels } & \text { Increased } & \text { Not increased } \\ \text { Fibrosis } & \text { Subepithelial } & \text { Peribronchiolar }\end{array}$

Th: T-helper; Tc: T-cytotoxic. 


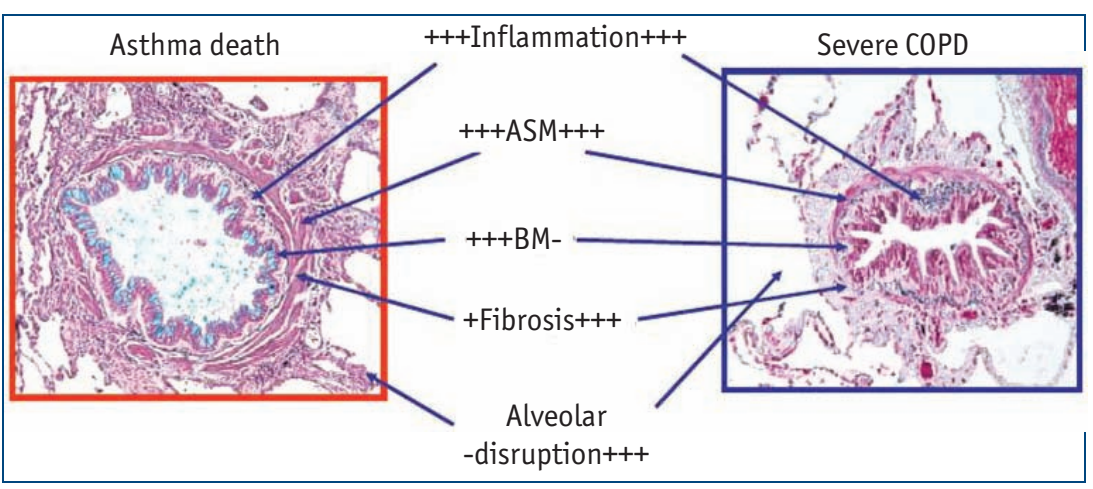

\section{Figure 3}

Contrasting histopathology of asthma and chronic obstructive pulmonary disease (COPD). A small airway from a patient who died from asthma and a similar sized airway from a patient with severe COPD are shown. There is an infiltration with inflammatory cells in both diseases. The airway smooth muscle (ASM) layer is thickened in asthma but only to a minimal degree in COPD. The basement membrane (BM) is thickened in asthma due to collagen deposition (subepithelial fibrosis) but not in COPD, whereas in COPD collagen is deposited mainly around the airway (peribronchiolar fibrosis). The alveolar attachments are intact in asthma, but disrupted in COPD as a result of emphysema. Images courtesy of J. Hogg (Vancouver, Canada).

the number of eosinophils in the blood and sputum does not reduce airway hyperresponsiveness or asthma symptoms $[22,23]$. As discussed previously, eosinophilic bronchitis is not associated with airway hyperresponsiveness, but subepithelial fibrosis does occur, which suggests a role for eosinophils in airway fibrosis. Interestingly, the presence of eosinophils seems to be a good marker of steroid responsiveness [24]. Neutrophils are increased in the sputum of patients with COPD and this correlates with disease severity [25]. The increase in neutrophils is related to an increase in the production of CXC-chemokines, such as CXC-chemokine ligand 1 (CXCL1, also known as GRO $\alpha$ ) and CXCL8 (also known as IL-8), which act on CXCR2 expressed predominantly on neutrophils.

\section{Macrophages}

Macrophage numbers are increased in the lungs of patients with asthma and COPD, but their numbers are far greater in COPD than in asthma. These macrophages are derived from circulating monocytes, which migrate to the lungs in response to chemoattractants such as CCL2 (also known as monocyte chemoattractant protein (MCP) 1) acting on CCR2 and CXCL1 acting on CXCR2 [26]. There is increasing evidence that lung macrophages orchestrate the inflammation of COPD through the release of chemokines that attract neutrophils, monocytes and T-cells, and the release of proteases, particularly MMP9 [27]. The pattern of inflammatory cells found in the respiratory tract therefore differs in patients with asthma and those with COPD and some of these contrasts may be explained by differences in the immunological mechanisms driving these two diseases.

\section{Immune responses}

The immune mechanisms that drive the different inflammatory processes of asthma and COPD are mediated by different types of immune cell, in particular by different T-cell subsets. An understanding of which immune cells are involved is now emerging and may lead to the development of new and more specific therapies for airway diseases in the future (figs 1 and 2).

\section{T-cells}

In asthmatic patients, there is an increase in the number of CD4+ T-cells in the airways and these are predominantly $\mathrm{T}$ helper (Th) type 2 cells, whereas, in normal airways Th-1 cells predominate [28]. By secreting the cytokines IL-4 and IL13 , which drive immunoglobulin (Ig)E production by B-cells, IL-5, which is solely responsible for eosinophil differentiation in the bone marrow, and IL-9, which attracts and drives the differentiation of mast cells [29], Th-2 cells have a central role in allergic inflammation and therefore their regulation is an area of intense research.

The transcription factor GATA3 (GATA-binding protein 3 ) is crucial for the differentiation of uncommitted naïve T-cells into Th-2 cells and it also regulates the secretion of Th-2-type cytokines $[30,31]$. Accordingly, there is an increase in the number of GATA3+ T-cells in the airways of asthmatic subjects compared with normal subjects $[32,33]$. Following simultaneous ligation of the T-cell receptor (TCR) and co-receptor, CD28, by antigen-presenting cells, GATA3 is phosphorylated and activated by p38 mitogenactivated protein kinase (MAPK). Activated GATA3 then translocates from the cytoplasm to the nucleus, where it activates gene transcription [34]. GATA3 expression in T-cells is regulated by the transcription factor signal transducer and activator of transcription (STAT)6 via IL-4 receptor activation. For Th-1-cell differentiation and secretion of the Th-1-type cytokine, interferon (IFN)- $\gamma$, the crucial transcription factor is T-bet. Consistent with the prominent role of Th-2 cells in asthma, T-bet expression is reduced in T-cells from the airways of asthmatic patients compared with non-asthmatic patients [35]. When phosphory- 
lated, T-bet can associate with and inhibit the function of GATA3, by preventing it from binding to its DNA target sequences [36]. T-betdeficient mice show increased expression of GATA3 and production of Th-2-type cytokines, confirming that T-bet is an important regulator of GATA3 [35]. GATA3 expression is also regulated by IL27 , a recently identified member of the IL-12 family, which downregulates GATA3 expression and upregulates T-bet expression, thereby favouring the production of Th-1-type cytokines, which then act to further inhibit GATA3 expression [37]. In turn, GATA3 inhibits the production of Th-1-type cytokines by inhibiting STAT4, the major transcription factor activated by the T-betinducing cytokine IL-12 [38]. Nuclear factor of activated T-cells (NFAT) is a T-cell-specific transcription factor and appears to enhance the transcriptional activation of GATA3 at the IL-4 promoter [39]. Finally, IL-33, a newly discovered member of the IL-1 family of cytokines, seems to promote Th-2-cell differentiation by translocating to the nucleus and regulating transcription through an effect on chromatin structure [40], but it also acts as a selective chemoattractant of Th-2 cells by binding the surface receptor IL-1 receptor-like 1 (also known as ST2), which is specifically expressed by these cells [41].

In contrast to asthma, the CD4+ T-cells that accumulate the airways and lungs of patients with COPD are mainly Th-1 cells. Th-1 cells express the chemokine receptor CXCR3 [42] and may be attracted to the lungs by the IFN- $\gamma$ induced release of the CXCR3 ligands CXCL9 (also known as MIG), CXCL10 (also known as IP10) and CXCL12 (also known as I-TAC), which are present at high levels in COPD airways [42, 43]. However, there is some evidence that Th-2 cells are also increased in lavage fluid of patients with COPD [44]; likewise, in patients with more severe asthma Th-1 cells are activated, as well as Th-2 cells [45], making the distinction between the Th-cell patterns in these two diseases less clear.

Other subtypes of CD4+ T-cells that may play an important role in airway diseases are regulatory T-cells, which have a suppressive effect on other CD4+ T-cells and may play a role in regulating Th-2-cell function in asthma $[28$, 46]. There is evidence that the numbers of CD4+CD25+ regulatory T-cells that express the transcription factor forkhead box P3 (FOXP3) are reduced in individuals with allergic rhinitis (hay fever) compared with non-atopic individuals, and this may be important in enabling high numbers of Th-2 cells to develop in allergic disease [47]. However, by contrast, asthmatic patients seem to have an increase in FOXP3expressing regulatory T-cells compared with patients with mild asthma, at least among circulating cells [48]. Analysis of sputum from COPD patients suggests that the numbers of CD4+CD25+FOXP3+ regulatory T-cells are reduced, but similar changes are also seen in people who smoke that do not have airflow obstruction [49]. So, the role of regulatory T-cells in asthma and COPD remains unclear and further research is therefore needed, particularly in defining the role of different types of regulatory T-cells [50].

Another subset of CD4+ T-cells, known as Th17 cells, has recently been described and shown to have an important role in inflammatory and autoimmune diseases [51, 52]. Little is known about the role of Th-17 cells in asthma or COPD, but increased concentrations of IL-17 (the predominant product of Th-17 cells) have been reported in the sputum of asthma patients [53]. IL-17A and the closely related cytokine IL-17F have been linked to neutrophilic inflammation by inducing the release of CXCL1 and CXCL8 from airway epithelial cells [54]. As well as IL-17, Th-17 cells also produce IL-21, which is important for the differentiation of these cells and thus acts as a positive autoregulatory mechanism, but it also inhibits FOXP3 expression and regulatory T-cell development $[55,56]$. Another cytokine, IL22 , is also released by these cells and stimulates the production of IL-10 and acutephase proteins [57].

However, more work is needed to understand the role and regulation of Th-17 cells in asthma and COPD, as they may represent important new targets for future therapies. A subset of CD4+ T-cells termed invariant natural killer T (iNKT) cells, which secrete IL-4 and IL-13, has been shown to account for $60 \%$ of all CD4+ T-cells in bronchial biopsies from asthmatic patients [58], but this has been disputed in another study, which failed to show any increase in iNKT-cell numbers in bronchial biopsies, bronchoalveolar lavage or sputum of either asthma or COPD patients [59]. The role of iNKTcells in asthma is currently uncertain, as there appears to be a discrepancy between the data from murine models of asthma and humans with the disease [28].

CD8+ T-cells predominate over CD4+ T-cells in the airways and lung parenchyma of patients with COPD [60], but their role in disease pathogenesis is not yet certain. Type 1 cytotoxic $\mathrm{T}$ (TC1) cells, which secrete IFN- $\gamma$, predominate 
and express CXCR3, suggesting that they are attracted to the lungs by CXCR3-binding chemokines [44, 61]. These CXCR3 ligands suppress CCR3, the receptor for CCL11, suggesting that they might suppress eosinophilic inflammation [62]. The production of CCL5 (also known as RANTES), which attracts CD4+ and CD8+ T-cells via CCR5, is also increased in the sputum of COPD patients compared with controls and may also be involved in T-cell recruitment [44]. TC1 cells release granzyme B and perforins, which are also present at higher levels in the sputum of COPD patients than in normal control subjects who also smoke [63], and may induce apoptosis of type 1 pneumocytes, thereby contributing to the development of emphysema [15]. TC1- and Th-1-cell-driven inflammation is likely to be self-perpetuating as IFN- $\gamma$ stimulates the release of CXCR3 ligands, which then attract more Th-1 and TC1 cells into the lungs (fig. 4). TC2 cells, which secrete IL-4, have also been described in COPD [45]. In asthma, CD8+ T-cells are present in patients with more severe disease and irreversible airflow obstruction [64] and these cells may be of either the TC1 or TC2 type [65].

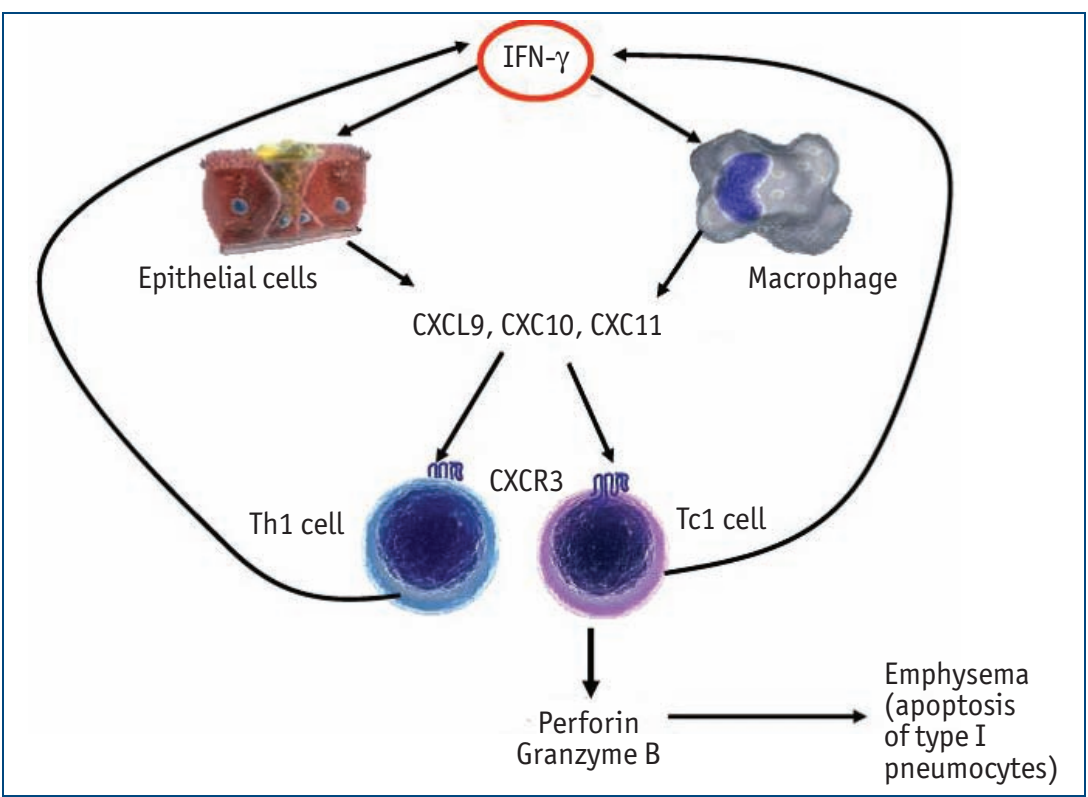

\section{Figure 4}

CD8+ T-cells in chronic obstructive pulmonary disease (COPD). Epithelial cells and macrophages are stimulated by interferon- $\gamma$ (IFN) to release the chemokines CXC-chemokine ligand 9 (CXCL9), CXCL10 and CXCL11, which together act on CXC-chemokine receptor 3 (CXCR3) expressed on $T$ helper 1 (Th1) cells and type 1 cytotoxic $T$ (TC1) cells to attract them into the lungs. TC1 cells, through the release of perforin and granzyme B, induce apoptosis of type 1 pneumocytes, thereby contributing to emphysema. IFN released by Th1 and Tc1 cells then stimulates further release of CXCR3 ligands, resulting in a persistent inflammatory activation.

\section{B-cells}

B-cells have an important role in allergic diseases, including asthma, through the release of allergen-specific IgE which binds to high-affinity Fc receptors (FceRI) on mast cells and basophils and to low-affinity Fc receptors (FcERII) on other inflammatory cells, including B-cells, macrophages and possibly eosinophils [66]. The Th-2type cytokines IL-4 and IL-13 induce B-cells to undergo class switching to produce lgE. Blocking IgE with a monoclonal antibody, omalizumab, reduces the response to allergens, airway inflammation and asthma exacerbations, indicating that IgE drives allergic inflammation in asthma [67]. In both atopic asthma and non-atopic asthma, IgE may be produced locally by B-cells in the airways [68].

Interestingly, IgE secretion is not observed in patients with COPD; however, in the peripheral airways of patients with more severe disease, there is a marked increase in the number of Bcells, which are organised into lymphoid follicles that are surrounded by T-cells [13]. The class of immunoglobulin they secrete and how they are regulated is currently unknown, but they may be activated by bacterial or viral antigens as a consequence of the chronic bacterial colonisation or latent viral infection in the airways of these patients. Alternatively, it has been suggested that COPD might have an autoimmunecomponent with the development of new antigenic epitopes as a result of the tissue damage induced by cigarette smoking, oxidative stress or chronic bacterial infection [16, 69]. CD4+ T-cells isolated from the lungs of patients with severe emphysema are oligoclonal, which is consistent with antigenic stimulation by infective organisms or autoimmunity [70]. In a mouse model of emphysema induced by tobacco smoke, an autoimmune mechanism has been proposed with a role for neutrophilelastase-specific antibodies [71].

\section{Dendritic cells}

Dendritic cells (DCs) have an important role in asthma as regulators of Th-2 cells and in the presentation of processed peptides from inhaled allergens to Th-2 cells [72]. They are not only involved in the initial sensitisation to allergens, but also in driving the chronic inflammatory response in the lungs and therefore provide a link between allergen exposure and allergic inflammation in asthma. The cytokine thymic stromal lymphopoietin (TSLP), which is secreted 
Table 2 Comparison between asthma and chronic obstructive pulmonary disease (COPD) inflammation patterns

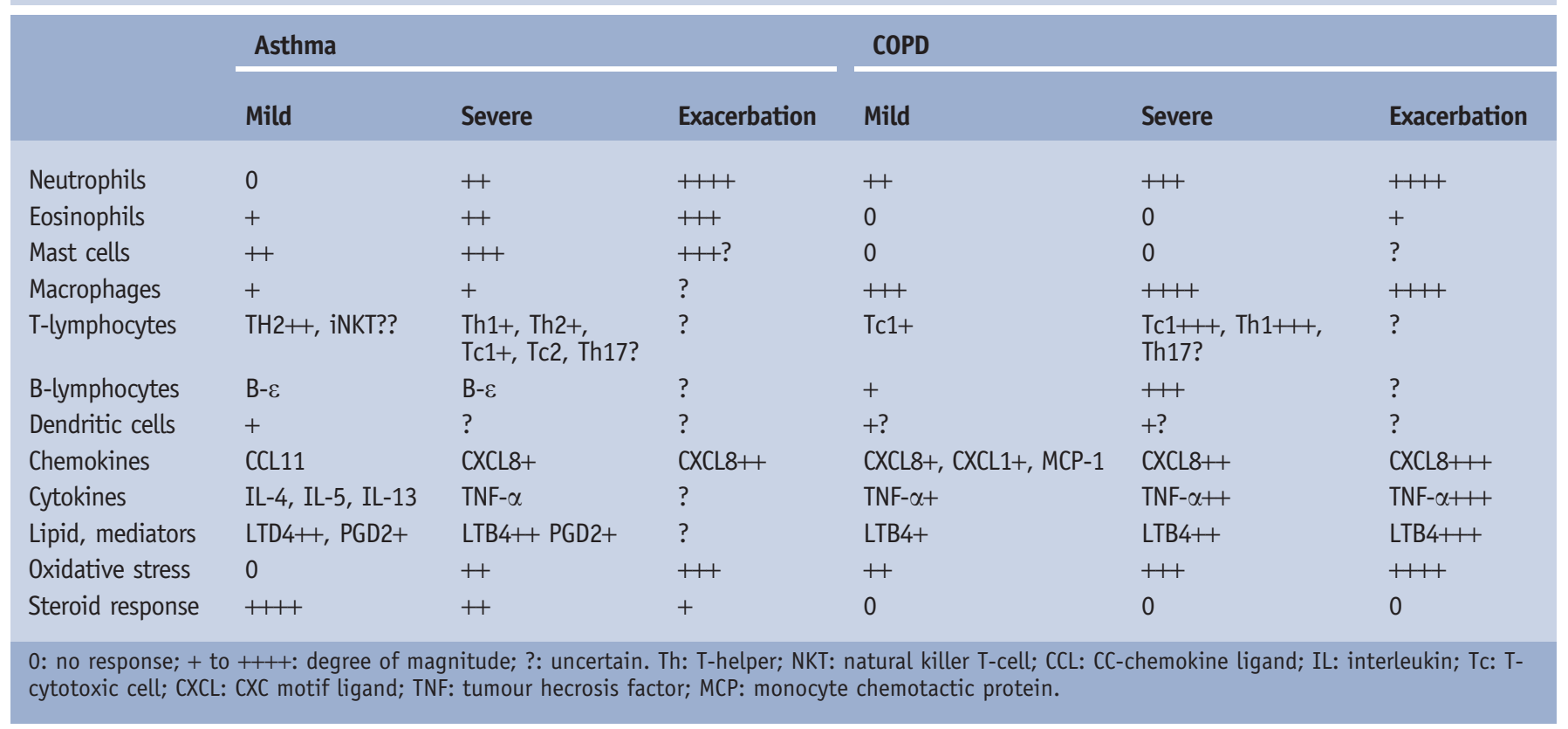

in large amounts by epithelial cells and mast cells of asthmatic patients $[73,74]$, may have a critical role in the maturation of myeloid DCs and the recruitment of Th-2 cells to the airways by inducing the release of CCL17 (also known as TARC) and CCL22 (also known as MDC), which bind to CCR4 that is selectively expressed by Th-2 cells [75].

Cigarette smoking is associated with an expansion of the DC population and with a marked increase in the number of mature DCs in the airways and alveolar walls of people who smoke [76]. The role of DCs in COPD is currently unclear as there are no obvious antigenic stimulants as there are in asthma; however, $\alpha$ glycoprotein, isolated from tobacco, is known to have a powerful immunestimulatory effect. Alternatively, a recent electron microscopy study has demonstrated a decrease in DCs is the airways of patients with COPD who smoke compared with smokers without airway obstruction, suggesting that they do not play a key role in COPD [77]. Conversely, another study shows a clear increase in the numbers of dendritic cells in COPD patients, indicating that they may play a role in linking innate and acquired immunity [78].

\section{Similarities between asthma and COPD}

Although the inflammatory and immune mechanisms of asthma and COPD described above are markedly different, there are several situations where they become more similar and the distinction between asthma and COPD becomes blurred (table 2).

\section{Severe asthma}

Although only about $5 \%$ of the asthmatic population develop severe disease, such cases account for over half of the healthcare spending in asthma and they are poorly controlled by currently available therapies [79]. The inflammatory pattern occurring in severe asthma becomes more similar to that occurring in COPD than in mild asthma, with increased numbers of neutrophils in the sputum, together with increased amounts of CXCL8 and tumournecrosis factor [80], increased oxidative stress and a poor response to corticosteroids as is observed in patients with COPD (table 2). Moreover, whereas in mild asthma Th-2 cells predominate, in more severe disease there is a mixture of Th-1 and Th-2 cells present in bronchial biopsies, as well as more CD8+ T-cells and this more closely resembles the immunecell infiltration seen in COPD $[46,64,65]$. The neutrophilic inflammation seen in cases of severe asthma may by induced by IL-17 production by Th-17 cells, which induces the release of the neutrophilic chemokine CXCL8 from airway epithelial cells $[54,55]$. A neutrophilic pattern of inflammation, with high levels of CXCL8, is also found in the sputum of asthmatic individuals who smoke [81]. Similar to patients with severe disease or COPD, these 
individuals also have a poor response to corticosteroids, even if given orally in high doses.

\section{Reversible COPD}

Approximately $10 \%$ of patients with COPD patients have a reversibility of bronchoconstriction, showing $>12 \%$ improvement in lung function as assessed by forced expiratory volume in $1 \mathrm{~s}(\mathrm{FEV} 1)$, and therefore behave more like asthmatics. Furthermore, compared with most patients with COPD, these patients more frequently have eosinophils in their sputum, an increase in exhaled nitric oxide and respond better to corticosteroid treatment, all of which are features of asthma $[82,83]$. It therefore seems likely that these patients have concomitant asthma and COPD.

\section{Acute exacerbations}

Acute exacerbations (worsening of symptoms) occur in patients with asthma and COPD, and are a major cause of patient suffering and medical expenditure $[84,85]$. Exacerbations in asthmatic individuals are usually triggered by upper respiratory tract infections, such as with rhinoviruses, and less commonly by inhaled allergens and air pollutants, whereas exacerbations in patients with COPD are usually triggered by either bacteria or viral infections. In both diseases, exacerbations are associated with a further increase in airway inflammation, increased numbers of cells infiltrating the lungs and higher concentrations of inflammatory mediators than are present in the stable state. However, there may also be changes in the pattern of inflammation. In exacerbations of asthma triggered by viruses, there can be increases in the numbers of neutrophils, as well as of eosinophils [84], whereas in COPD exacerbations, particularly those due to viruses, there may be an increase in eosinophil numbers [86]. So, during episodes of disease exacerbation, the pattern of inflammation becomes similar in COPD and asthma.

\section{References}

1. Kraft M. Asthma and chronic obstructive pulmonary disease exhibit common origins in any country! Am J Respir Crit Care Med 2006; 174: 238-240.

2. Barnes PJ. Against the Dutch hypothesis: asthma and chronic obstructive pulmonary disease are distinct diseases. Am J Respir Crit Care Med 2006; 174: 240-243.

3. Barnes PJ. Mechanisms in COPD: differences from asthma. Chest 2000; 117: 10S-14S.

4. Jeffery PK. Comparison of the structural and inflammatory features of COPD and asthma. Chest 2000; 117: 251S-260S.

5. Wenzel SE. Asthma: defining of the persistent adult phenotypes. Lancet. 2006; 368: 804-13.

6. Phelan PD, Robertson CF, Olinsky A. The Melbourne Asthma Study: 1964-1999. J Allergy Clin Immunol 2002; 109: 189-194.

7. Barnes PJ. Immunology of asthma and chronic obstructive pulmonary disease. Nat Immunol Rev 2008; 8: $183-192$.

8. Barnes PJ. Mediators of chronic obstructive pulmonary disease. Pharm Rev 2004; 56: 515-548.

9. Barnes PJ. Cytokine networks in asthma and chronic obstructive pulmonary disease. J Clin Invest 2008; 118: 3546-3556.

10. Siddiqui S, Sutcliffe A, Shikotra A, et al. Vascular remodeling is a feature of asthma and nonasthmatic eosinophilic bronchitis. J Allergy Clin Immunol 2007; 120: 813-819.

11. Ordonez CL, Khashayar R, Wong $\mathrm{HH}$, et al. Mild and moderate asthma is associated with airway goblet cell hyperplasia and abnormalities in mucin gene expression. Am J Respir Crit Care Med 2001; 163: $517-523$.

12. Hogg JC. Pathophysiology of airflow limitation in chronic obstructive pulmonary disease. Lancet 2004; 364 : 709-721.

13. Hogg JC, Chu F, Utokaparch S, et al. The nature of small-airway obstruction in chronic obstructive pulmonary disease. New Engl J Med 2004; 350: 2645-2653.

14. Caramori G, Di Gregorio C, Carlstedt I, et al. Mucin expression in peripheral airways of patients with chronic obstructive pulmonary disease. Histopathol 2004; 45: 477-484.

15. Majo J, Ghezzo H, Cosio MG. Lymphocyte population and apoptosis in the lungs of smokers and their relation to emphysema. Eur Respir J 2001; 17: 946-953.

16. Taraseviciene-Stewart L, Douglas IS, et al. Is alveolar destruction and emphysema in chronic obstructive pulmonary disease an immune disease? Proc Am Thorac Soc 2006; 3: 687-690.

17. Ohnishi K, Takagi M, Kurokawa Y, et al. Matrix metalloproteinase-mediated extracellular matrix protein degradation in human pulmonary emphysema. Lab Invest 1998; 78: 1077-1087.

18. Tuder RM, Yoshida T, Arap W, et al. State of the art. Cellular and molecular mechanisms of alveolar destruction in emphysema: an evolutionary perspective. Proc Am Thorac Soc 2006; 3: 503-510.

19. Reber L, Da Silva CA, Frossard N. Stem cell factor and its receptor C-Kit as targets for inflammatory diseases. Eur J Pharmacol 2006; 533: 327-340.

20. Galli SJ, Kalesnikoff J, Grimbaldeston MA, et al. Mast cells as "tunable" effector and immunoregulatory cells: recent advances. Annu Rev Immunol 2005; 23: 749-786.

21. Brightling CE, Bradding P, Symon FA, et al. Mast-cell infiltration of airway smooth muscle in asthma. $N$ Engl $\mathrm{J}$ Med 2002; 346: 1699-1705. 
22. Leckie MJ, ten Brincke A, Khan J, et al. Effects of an interleukin-5 blocking monoclonal antibody on eosinophils, airway hyperresponsiveness and the late asthmatic response. Lancet 2000; 356: 2144-2148.

23. Flood-Page P, Swenson C, Faiferman I, et al. A study to evaluate safety and efficacy of mepolizumab in patients with moderate persistent asthma. Am J Respir Crit Care Med 2007; 176: 1062-1071.

24. Green RH, Brightling CE, Woltmann G, et al. Analysis of induced sputum in adults with asthma: identification of subgroup with isolated sputum neutrophilia and poor response to inhaled corticosteroids. Thorax 2002; 57: 875-879.

25. Keatings VM, Collins PD, Scott DM, et al. Differences in interleukin-8 and tumor necrosis factor-a in induced sputum from patients with chronic obstructive pulmonary disease or asthma. Am J Respir Crit Care Med 1996; 153: 530-534.

26. Traves SL, Smith SJ, Barnes PJ, et al. Specific CXC but not CC chemokines cause elevated monocyte migration in COPD: a role for CXCR2. J Leukoc Biol 2004; 76: 441-450.

27. Barnes PJ. Macrophages as orchestrators of COPD. J COPD 2004; 1: 59-70.

28. Meyer EH, DeKruyff RH, Umetsu DT. T Cells and NKT Cells in the Pathogenesis of Asthma. Annu Rev Med 2008; 59: 281-292.

29. Kay AB. The role of T lymphocytes in asthma. Chem Immunol Allergy 2006; 91: 59-75.

30. Ho IC, Pai SY. GATA-3 - not just for Th-2 cells anymore. Cell Mol Immunol 2007; 4: 15-29.

31. Barnes PJ. Role of GATA-3 in allergic diseases. Curr Mol Me 2008; 8: 330-334.

32. Caramori G, Lim S, Ito K, et al. Expression of GATA family of transcription factors in T-cells, monocytes and bronchial biopsies. Eur Respir J 2001; 18: 466-473.

33. Nakamura Y, Ghaffar 0, Olivenstein R, et al. Gene expression of the GATA-3 transcription factor is increased in atopic asthma. J Allergy Clin Immunol 1999; 103: 215-222.

34. Maneechotesuwan $\mathrm{K}, \mathrm{X}$ in $\mathrm{Y}$, Ito K, et al. Regulation of Th-2 cytokine genes by $\mathrm{p} 38$ MAPK-mediated phosphorylation of GATA-3. J Immunol 2007; 178: 2491-2498.

35. Finotto $\mathrm{S}$, Neurath MF, Glickman JN, et al. Development of spontaneous airway changes consistent with human asthma in mice lacking T-bet. Science 2002; 295: 336-338.

36. Hwang ES, Szabo SJ, Schwartzberg PL, et al. T helper cell fate specified by kinasemediated interaction of T-bet with GATA-3. Science 2005; 307: 430-433.

37. Yoshimoto T, Yoshimoto T, Yasuda K, et al. IL-27 Suppresses Th-2 Cell Development and Th-2 Cytokines Production from Polarized Th-2 Cells: A Novel Therapeutic Way for Th-2-Mediated Allergic Inflammation. J Immunol 2007; 179: 4415-4423.

38. Usui T, Preiss JC, Kanno Y, et al. T-bet regulates Th1 responses through essential effects on GATA-3 function rather than on IFNG gene acetylation and transcription. J Exp Med 2006; 203: 755-766.

39. Avni 0 , Lee $D$, Macian $F$, et al. $T_{H}$ cell differentiation is accompanied by dynamic changes in histone acetylation of cytokine genes. Nat Immunol 2002; 3: 643-651.

40. Carriere V, Roussel L, Ortega N, et al. IL-33, the IL-1-like cytokine ligand for ST2 receptor, is a chromatinassociated nuclear factor in vivo. Proc Natl Acad Sci USA 2007; 104: 282-287.

41. Komai-Koma M, Xu D, et al. IL-33 is a chemoattractant for human Th-2 cells. Eur J Immunol 2007; 37: 2779-2786.

42. Saetta M, Mariani M, Panina-Bordignon P, et al. Increased expression of the chemokine receptor CXCR3 and its ligand CXCL10 in peripheral airways of smokers with chronic obstructive pulmonary disease. Am J Respir Crit Care Med 2002; 165: 1404-1409.

43. Costa C, Rufino R, Traves SL, et al. CXCR3 and CCR5 chemokines in the induced sputum from patients with COPD. Chest 2008; 133: 26-33.

44. Barczyk A, Pierzchala W, Kon OM, et al. Cytokine production by bronchoalveolar lavage T lymphocytes in chronic obstructive pulmonary disease. J Allergy Clin Immunol 2006; 117: 1484-1492.

45. Kurashima K, Fujimura M, Myou S, et al. Asthma severity is associated with an increase in both blood CXCR3+ and CCR4+ T-cells. Respirology 2006; 11: 152-157.

46. Larche M. Regulatory T-cells in allergy and asthma. Chest 2007; 132: 1007-1014.

47. Ling EM, Smith T, Nguyen XD, et al. Relation of CD4+CD25+ regulatory T-cell suppression of allergen-driven T-cell activation to atopic status and expression of allergic disease. Lancet 2004; 363: 608-615.

48. Lee JH, Yu HH, Wang LC, et al. The levels of CD4+CD25+ regulatory T-cells in paediatric patients with allergic rhinitis and bronchial asthma. Clin Exp Immunol 2007; 148: 53-63.

49. Smyth LJ, Starkey C, Vestbo J, et al. CD4-regulatory cells in COPD patients. Chest 2007; 132: 156-163.

50. Wan YY, Flavell RA. Regulatory T-cells, transforming growth factor-beta, and immune suppression. Proc Am Thorac Soc 2007; 4: 271-276.

51. Stockinger B, Veldhoen M. Differentiation and function of Th17 T-cells. Curr Opin Immunol 2007; 19: 281-286.

52. Weaver CT, Harrington LE, Mangan PR, et al., Th17. an effector CD4 T-cell lineage with regulatory T-cell ties. Immunity 2006; 24: 677-688.

53. Bullens DM, Truyen E, Coteur L, et al. IL-17 mRNA in sputum of asthmatic patients: linking T-cell driven inflammation and granulocytic influx? Respir Res 2006; 7: 135.

54. Laan M, Lotvall J, Chung KF, et al. IL-17-induced cytokine release in human bronchial epithelial cells in vitro: role of mitogen-activated protein (MAP) kinases. Br J Pharmacol 2001; 133: 200-206.

55. Nurieva R, Yang XO, Martinez G, et al. Essential autocrine regulation by IL-21 in the generation of inflammatory Tcells. Nature 2007; 448: 480-483.

56. Spolski R, Leonard WJ. Interleukin-21: Basic biology and implications for cancer and autoimmunity. Annu Rev Immunol 2008; 26: 57-79.

57. Wolk K, Sabat R. Interleukin-22: a novel T- and NK-cell derived cytokine that regulates the biology of tissue cells. Cytokine Growth Factor Rev 2006; 17: 367-380.

58. Akbari 0, Faul JL, Hoyte EG, et al. CD4+ invariant Tcell- receptor+ natural killer T-cells in bronchial asthma. New Engl J Med 2006; 354: 1117-1129.

59. Vijayanand P, Seumois G, Pickard C, et al. Invariant natural killer T-cells in asthma and chronic obstructive pulmonary disease. N Engl J Med 2007; 356: 1410-1422.

60. Saetta M, Di Stefano A, Turato G, et al. CD8+ T-lymphocytes in peripheral airways of smokers with chronic obstructive pulmonary disease. Am J Respir Crit Care Med 1998; 157: 822-826.

61. Grumelli S, Corry DB, Song L-X, et al. An immune basis for lung parenchymal destruction in chronic obstructive pulmonary disease and emphysema. PLoS Med 2004; 1: 75-83. 
62. Xanthou G, Duchesnes CE, Williams TJ, et al. CCR3 functional responses are regulated by both CXCR3 and its ligands CXCL9, CXCL10 and CXCL11. Eur J Immunol 2003; 33: 2241-2250.

63. Chrysofakis G, Tzanakis N, Kyriakoy D, et al. Perforin expression and cytotoxic activity of sputum CD8+ lymphocytes in patients with COPD. Chest 2004; 125: 71-76.

64. van Rensen EL, Sont JK, Evertse CE, et al. Bronchial CD8 cell infiltrate and lung function decline in asthma. Am J Respir Crit Care Med 2005; 172: 837-841.

65. Cho SH, Stanciu LA, Holgate ST, et al. Increased interleukin-4, interleukin-5, and interferon-gamma in airway CD4+ and CD8+ T-cells in atopic asthma. Am J Respir Crit Care Med 2005; 171: 224-230.

66. Gould HJ, Beavil RL, Vercelli D. IgE isotype determination: epsilon-germline gene transcription, DNA recombination and B-cell differentiation. Br Med Bull 2000; 56: 908-924.

67. Avila PC. Does anti-IgE therapy help in asthma? Efficacy and controversies. Annu Rev Med 2007; 58: 185-203.

68. Takhar P, Corrigan CJ, Smurthwaite L, et al. Class switch recombination to IgE in the bronchial mucosa of atopic and nonatopic patients with asthma. J Allergy Clin Immunol 2007; 119: 213-218.

69. Agusti A, Macnee W, Donaldson K, et al. Hypothesis: does COPD have an autoimmune component? Thorax 2003; 58 : 832-834.

70. Sullivan AK, Simonian PL, Falta MT, et al. Oligoclonal CD4+ T-cells in the lungs of patients with severe emphysema. Am J Respir Crit Care Med 2005; 172: 590-596.

71. Lee SH, Goswami S, Grudo A, et al. Antielastin autoimmunity in tobacco smoking-induced emphysema. Nat Med 2007; 13: 567-569.

72. Hammad H, Lambrecht BN. Recent progress in the biology of airway dendritic cells and implications for understanding the regulation of asthmatic inflammation. J Allergy Clin Immunol 2006; 118: 331-336.

73. Ying S, O'Connor B, Ratoff J, et al. Thymic stromal lymphopoietin expression is increased in asthmatic airways and correlates with expression of Th-2-attracting chemokines and disease severity. J Immunol 2005; 174: 8183-8190.

74. Allakhverdi Z, Comeau MR, Jessup HK, et al. Thymic stromal lymphopoietin is released by human epithelial cells in response to microbes, trauma, or inflammation and potently activates mast cells. J Exp Med 2007; 204: 253-258.

75. Liu YJ. Thymic stromal lymphopoietin: master switch for allergic inflammation. J Exp Med 2006; 203: 269-273.

76. Soler P, Moreau A, Basset $F$, et al. Cigarette smoking-induced changes in the number and differentiated state of pulmonary dendritic cells/Langerhans cells. Am Rev Respir Dis 1989; 139: 1112-1117.

77. Rogers AV, Adelroth E, Hattotuwa K, et al. Bronchial mucosal dendritic cells in smokers and ex-smokers with COPD: an electron microscopic study. Thorax 2008; 63: 108-114.

78. Demedts IK, Bracke KR, Van Pottelberge G, et al. Accumulation of dendritic cells and increased CCL20 levels in the airways of patients with chronic obstructive pulmonary disease. Am J Respir Crit Care Med 2007; 175: 998-1005.

79. Wenzel SE, Busse WW. Severe asthma: lessons from the Severe Asthma Research Program. J Allergy Clin Immunol 2007; 119: 14-21.

80. Jatakanon A, Uasaf C, Maziak W, et al. Neutrophilic inflammation in severe persistent asthma. Am J Respir Crit Care Med 1999; 160: 1532-1539.

81. Thomson NC, Chaudhuri R, Livingston E. Asthma and cigarette smoking. Eur Respir J 2004; 24: 822-833.

82. Papi A, Romagnoli M, Baraldo S, et al. Partial reversibility of airflow limitation and increased exhaled NO and sputum eosinophilia in chronic obstructive pulmonary disease. Am J Respir Crit Care Med 2000; 162: 1773-1777.

83. Brightling CE, McKenna S, Hargadon B, et al. Sputum eosinophilia and the short term response to inhaled mometasone in chronic obstructive pulmonary disease. Thorax 2005; 60: 193-198.

84. Wark PA. Gibson PG. Asthma exacerbations . 3: Pathogenesis. Thorax 2006; 61: 909-915.

85. Celli BR, Barnes PJ. Exacerbations of chronic obstructive pulmonary disease. Eur Respir J 2007; 29: 1224-1238.

86. Papi A, Luppi F, Franco F, et al. Pathophysiology of exacerbations of chronic obstructive pulmonary disease. Proc Am Thorac Soc 2006; 3: 245-251. 